\title{
Do interspecific competition and salinity explain plant zonation in a tropical estuary?
}

\author{
Laís Samira Correia Nunes • \\ Antonio Fernando Monteiro Camargo
}

Received: 14 November 2015/Revised: 3 May 2016/Accepted: 7 May 2016/Published online: 23 May 2016

(C) Springer International Publishing Switzerland 2016

\begin{abstract}
Environmental gradients and competition influence aquatic macrophyte distribution in estuaries. The competition-to-stress hypothesis states that some species are excluded from lower estuaries (high salinity) due to abiotic stress and others from upper estuaries (low salinity) by competition. The growth of Crinum americanum L. and Spartina alterniflora Loisel. in monoculture (10:0/0:10) and mixed culture (5:5) under different salinity levels $(4 / 12 / 26)$ was analysed by a laboratory experiment $(3$ cultures $\times 3$ sediment types $\times 3$ replicate) to understand the role of competition and salinity on the distribution of these species in a tropical estuary as well as to verify whether the competition-to-stress hypothesis explains their zonation. We tested the hypothesis that $S$. alterniflora is not established in the upper estuary due to the effect of competition with $C$. americanum, whereas the latter presents restrictions to high salinity and has greater competitive ability in the upper estuary. Our data confirm the competition-to-stress
\end{abstract}

Guest editors: M. T. O’Hare, F. C. Aguiar, E. S. Bakker \& K. A. Wood / Plants in Aquatic Systems - a 21st Century Perspective

L. S. C. Nunes $(\bowtie)$ · A. F. M. Camargo

Departamento de Ecologia, Instituto de Biociências, Universidade Estadual Paulista, Avenida 24 A, 1515, Rio Claro, SP CEP 13506-900, Brazil e-mail: laiscorreianunes@gmail.com

A. F. M. Camargo

e-mail: antoniofmcamargo@gmail.com hypothesis but not as proposed originally. We conclude that abiotic stress (low nutrient availability) is responsible for the absence of S. alterniflora in the upper estuary and that the competition between the two species is responsible for the absence of $C$. americanum in the lower estuary.

Keywords Crinum americanum - Spartina alterniflora $\cdot$ Estuarine gradient $\cdot$ Aquatic macrophytes $\cdot$ Spatial distribution $\cdot$ Competitive interaction

\section{Introduction}

Estuaries have environmental gradients of nutrient availability, sediment type, water level and salinity; these are factors that influence species distribution because they provide different habitats for aquatic vegetation occupation (Bertness, 1991). Thus, aquatic vegetation is distributed with species adapted to higher salinity in the lower estuarine portion and species adapted to freshwater in the upper estuarine portion. In fact, salinity has been considered the main variable that determines the distribution of aquatic vegetation in coastal ecosystems (Burgos-Léon et al., 2013; Ribeiro et al., 2015; Rodríguez-Gallego et al., 2015). However, according to these same authors, other abiotic factors in addition to salinity such as sediment nutrient availability, variation in water level and light intensity are responsible for the distribution of aquatic 
plants in coastal environments (Burgos-Léon et al., 2013; Rodríguez-Gallego et al., 2015). Biotic interactions may also be important factors in the zonation of aquatic macrophytes in estuarine areas (Barbour, 1978; Crain et al., 2004; Engels \& Jensen, 2010; Guo \& Pennings, 2012), and the importance of these interactions can vary along the salinity gradient (Greenwood \& MacFarlane, 2009).

The distribution of aquatic macrophytes in estuaries can be explained by the competition-to-stress hypothesis. This hypothesis states that some species are excluded from the locations nearest to the seashore due to abiotic stress for their non-adaptation to higher values of salinity and flooding while other species are excluded from the locations most distant from the seashore in lower salinity areas due to competition (Crain et al., 2004; Engels \& Jensen, 2010). In fact, in many cases, salt tolerance and competitive ability can be inversely related (La Peyre et al., 2001). According to the competition-to-stress hypothesis, species with higher competitive ability but with restrictions to salinity would occupy oligohaline and freshwater areas while more salt-tolerant species (halophytes) and less-competitive species would occur in higher salinity areas (Crain et al., 2004). However, in the absence of competitors, many halophyte species can survive and occur throughout the estuarine salinity gradient (Bertness et al., 1992; Hellquist \& Black, 2010). Therefore, the importance of the influence of biotic and abiotic factors on plant distribution may vary depending on the environment and the species in question (French \& Chambers, 1996; La Peyre et al., 2001). Indeed, the competition-to-stress hypothesis did not explain the species distribution in the Altamaha River Estuary (Georgia, USA) according to Guo \& Pennings (2012). These authors demonstrated that multiple factors and processes are responsible in this estuary for the distribution of aquatic macrophytes and that the competition-to-stress hypothesis simplifies these complex processes in estuarine regions.

The estuaries of southeastern Brazil are colonized by various aquatic macrophytes species including Crinum americanum L. (Amaryllidaceae) and Spartina alterniflora Loisel. (Poaceae) (Tararam \& Wakabara, 1987; Biudes \& Camargo, 2006; Ribeiro et al., 2011). In areas with low or no influence of saltwater in the Itanhaém River Basin (Southeastern Brazil), several aquatic macrophyte species of different life forms occur. In areas with higher salinity (estuary), there are mangrove shrub species (Rhizophora mangle L., Laguncularia racemosa (L.) C. F. Gaertn. and Avicennia sp. L.). In the Itanhaém River Estuary, the aquatic macrophytes $C$. americanum and $S$. alterniflora are distributed with $S$. alterniflora forming monospecific banks in the lower portion, C. americanum monospecific banks in the upper portion and banks containing the two species in the estuarine intermediate portion. However, $S$. alterniflora is absent and $C$. americanum is widely distributed in another estuary with very similar characteristics and located near the Itanhaém River Estuary (Ribeiro et al., 2011). In high latitudes, salinity and competition influence the growth of $S$. alterniflora. For example, Crain et al. (2004) observed that this species is limited by competition in freshwater habitats, and Medeiros et al. (2013) observed high growth of $S$. alterniflora in places with a high-salinity level and even in competition with Phragmites australis. The influence of biotic and abiotic factors on the spatial distribution of aquatic macrophytes in general and particularly on S. alterniflora in tropical estuaries is still contradictory. The lack of experimental studies on plant zonation in tropical estuarine regions can lead to a generality of the competition-to-stress hypothesis, which was suggested in middle and high latitudes, and to its inadequacy for other geographical zones. Therefore, an experimental study with $C$. americanum and $S$. alterniflora can help demonstrate the importance of biotic and abiotic factors on macrophyte distribution in tropical estuaries.

Thus, the aims of this study were to understand what mechanisms are responsible for the spatial distribution of $C$. americanum and $S$. alterniflora in the Itanhaém River Estuary, especially competition and salinity, and to verify whether the competition-tostress hypothesis explains the distribution of these two species. The hypothesis we tested was that the halophyte $S$. alterniflora could develop in low-salinity environments, but it would not be established in the oligohaline environment due to the competition effect with $C$. americanum. Meanwhile, $C$. americanum would not tolerate higher salinity (salt stress) but would have greater competitive ability in low-salinity environments. To test this hypothesis, we conducted a laboratory experiment evaluating the growth of these species. 


\section{Materials and methods}

Study area

The estuarine region of the Itanhaém River Basin (southern coast of São Paulo State, Southeastern Brazil) (Fig. 1) is influenced by a tidal regime with a mixture of freshwater and saltwater that sets a salinity gradient in the rivers (Camargo et al., 2002). The study area is characterized by a small seasonal variation in climate (mean summer precipitation $=256.4 \mathrm{~mm}$ and mean winter precipitation $=92.7 \mathrm{~mm}$; mean summer temperature $=27.9^{\circ} \mathrm{C}$ and mean winter temperature $=21.1^{\circ} \mathrm{C}$ ) and limnologic characteristics, the absence of seasonal flooding pulses, a small change in the water level due to micro-tides (maximum tidal amplitude of $1.50 \mathrm{~m}$ ) and rainfall in short time periods (Camargo \& Florentino, 2000).

Crinum americanum and S. alterniflora banks occur in three portions along the estuarine salinity gradient. Monospecific banks of S. alterniflora are located in the lower estuarine portion from the estuary mouth to approximately $5 \mathrm{~km}$ upstream (Euryhaline condition/Lower estuary). Mixed banks of C. americanum and S. alterniflora are located in the intermediate portion between 5 and $6 \mathrm{~km}$ from the estuary mouth (Mesohaline condition/Middle estuary), and monospecific banks of $C$. americanum are located in the upper estuarine portion between 6 and $12 \mathrm{~km}$ from the estuary mouth (Oligohaline condition/Upper estuary) (Fig. 1).

\section{Experiment}

We developed a completely randomized experiment lasting 174 days (when the biomass of all treatments became constant) in a greenhouse comprising two factors (culture $\times$ sediment type) to evaluate the growth of both species under different salinity levels and in monoculture and mixed culture. We used three
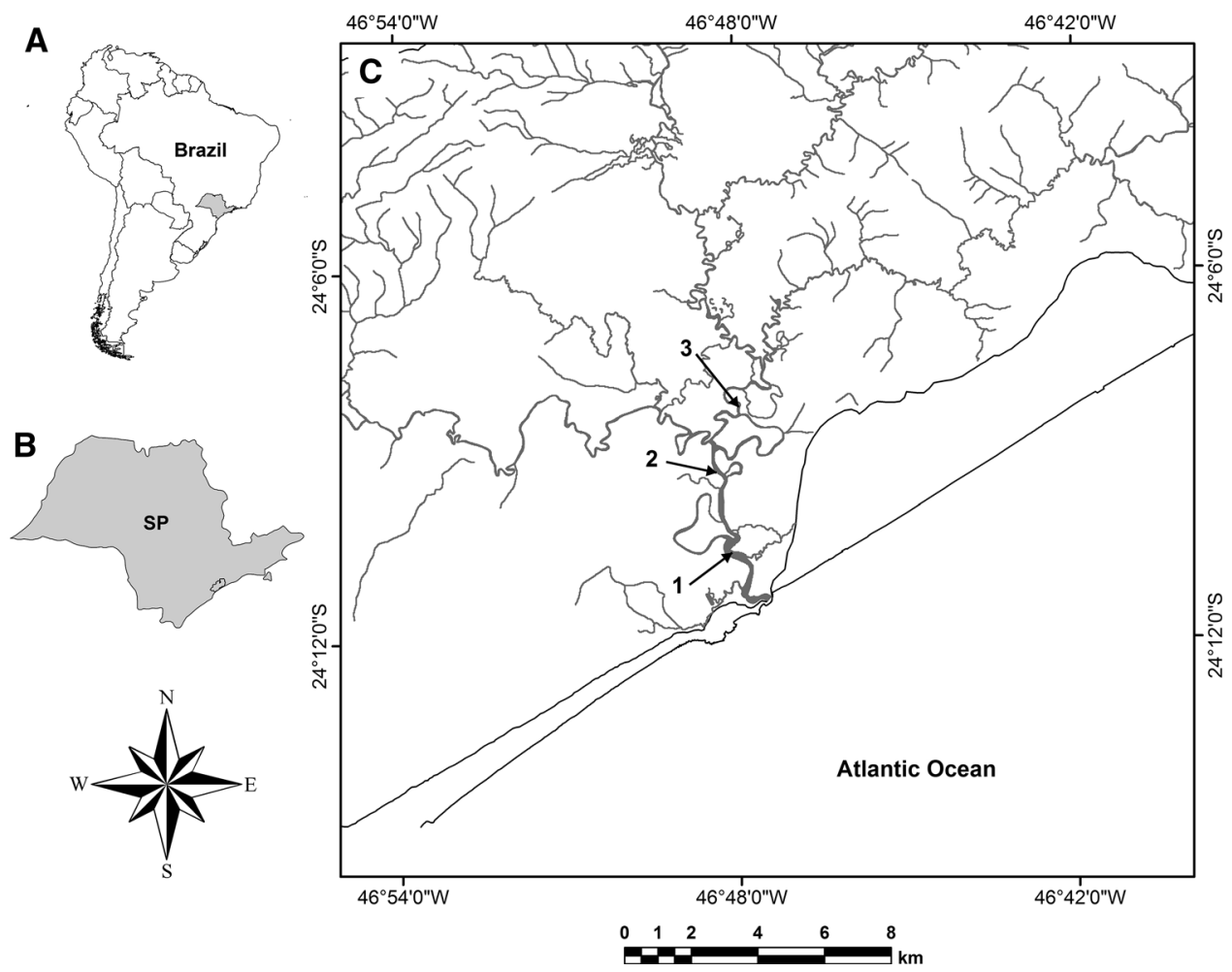

Fig. 1 The maps of South America (A) and São Paulo STATE (B), highlighting the Itanhaém River Estuary Drainage (C). The black arrows indicate the locations of the aquatic macrophytes banks. 1 Monospecific banks of S. alterniflora in the lower estuary, 2 mixed banks of S. alterniflora and C. americanum in the middle estuary and 3 monospecific banks of $C$. americanum in the upper estuary 
salinity levels in monospecific cultures of $C$. americanum and $S$. alterniflora and in mixed culture with the two species. The sediment used as a substrate to evaluate the plant growth in the experiment was collected near the banks of the two species located in the lower, middle and upper portions of the Itanhaém River Estuary. In the same places, we collected sediment samples in triplicate to determine the salinity level (salinometer PS Corning), total nitrogen (Mackereth et al., 1978), total phosphorus (Golterman et al., 1978), organic matter percentage (mufla oven incineration) and granulometry (Suguio, 1973).

We collected young $(0.50 \mathrm{~m})$ and healthy $C$. americanum and $S$. alterniflora individuals from the intermediate estuarine portion. The individuals were then planted in plastic boxes (experimental units) with a volume of 261 and an area of $0.13 \mathrm{~m}^{2}$ in triplicate. The initial total density, similar to that observed in the field, was 10 individuals per experimental unit, 10:0 and 0:10 in the monoculture treatments and 5:5 in the mixed culture treatment $(3$ cultures $\times 3$ sediment types $\times 3$ replicas $=27$ experimental units). The experimental units were watered with tap water to maintain the approximate level of $2.0 \mathrm{~cm}$ above the sediment surface, similar to the adapted method of La Peyre et al. (2001). The values of salinity, total nitrogen, total phosphorus and organic matter percentage were not monitored throughout the experiment.

To estimate the plant aboveground and belowground biomass in the experiment, we collected 70 individuals each of $C$. americanum and $S$. alterniflora of different sizes. In the laboratory, we obtained the width and length measurements of the leaves for calculating the aboveground fraction area through the calculation formula of a triangular area for the two species, which provides the most approximate geometry of the species leaves. For S. alterniflora, we also determined stem length and the average stem perimeter of each individual (cylinder side area) to calculate the stem area. For the belowground fraction, we obtained root and rhizome volumes by measuring water displacement in a graduated recipient. The plants were dried in an oven at $60^{\circ} \mathrm{C}$ to constant weight. We estimated the aboveground and belowground fraction dry weight of the two species by a simple linear regression equation between area and dry mass (Eqs. 1,2) and between volume and dry mass (Eqs. 3, 4), respectively. The models we found were:
C. americanum aboveground DM

$$
=87.079 \times \text { area }-0.3672\left(R^{2}=0.8329\right)
$$

S. alterniflora aboveground DM

$$
=180.6353 \times \text { area }-0.06458\left(R^{2}=0.8343\right)
$$

C. americanum belowground DM

$$
=0.0504 \times \text { volume }+1.241\left(R^{2}=0.9315\right)
$$

\section{S. alterniflora belowground DM}

$$
=0.0932 \times \text { volume }+0.3244\left(R^{2}=0.7965\right)
$$

After planting, we waited 15 days for the aquatic macrophytes to acclimatize, and then we performed measurements of the plant aboveground area on days 16, 31, 55, 70, 84, 97, 118, 142 and 174. The belowground volume was assessed at the beginning and at the end of the experiment against the initial data corresponding to the date of planting (day 0). To obtain the values of the plant aboveground and belowground biomass, we used the regression equations cited above.

The simple linear regression model between aboveground biomass and time was adjusted for each replicate of the variation in aboveground biomass of C. americanum and $S$. alterniflora in the treatments. The slope, that is, the measurement of "intensity" or "speed" growth through the regression line slope, was used to analyse the response of the plant aboveground biomass in the monocultures and mixed cultures under the three salinity levels.

To compare, in relative terms, the growth of the aboveground fraction of $C$. americanum and $S$. alterniflora in the mixed culture under different salinity levels, we calculated the values of the relative aboveground biomass (RAB) according to Kenkel et al. (1991) (Eq. 5).

$\mathrm{RAB}_{a x}=\mathrm{AB}_{a x} /\left(\mathrm{AB}_{a x}+\mathrm{AB}_{b x}\right)$,

where $\mathrm{RAB}_{a x}$ is the relative aboveground biomass of the species $a$ in mixed culture $x ; \mathrm{AB}_{a x}$ is the aboveground of the species $a\left(\mathrm{gDM} \mathrm{m}^{-2}\right)$ in mixed culture $x$; and $\mathrm{AB}_{b x}$ is the biomass of the species $b\left(\mathrm{gDM} \mathrm{m}^{-2}\right)$ in mixed culture $x$.

We evaluated the variation in plant belowground fraction in the experiment through the gain in belowground biomass using the following equation (Eq. 6): 
$\mathrm{GBB}_{\mathrm{a} x}=\mathrm{Bf}_{a x}-\mathrm{Bi}_{a x}$,

where $\mathrm{GBB}_{a x}$ is the gain in belowground biomass $\left(\mathrm{gDM} \mathrm{m}^{-2}\right)$ of the species $a$ in the treatment $x$; $\mathrm{Bf}_{a x}$ is the final biomass $\left(\mathrm{gDM} \mathrm{m}^{-2}\right)$ of the species $a$ in the treatment $x$; and $\mathrm{Bi}_{a x}$ is the initial biomass $\left(\mathrm{gDM} \mathrm{m}^{-2}\right)$ of the species $a$ in the treatment $x$.

\section{Data analysis}

We elaborated the aboveground fraction growth curves of the two species using the mean values and standard deviation of aboveground biomass and adjusted the variation in aboveground biomass to the linear regression model using GraphPad Prism 5.0 software (GPW5066646-RCG7389) (GraphPad Software, 2007).

Then, we verified the existence of significant differences $(P<0.05)$ among the slope values of the variation in aboveground biomass and among the gain in the belowground biomass of $C$. americanum and $S$. alterniflora under different cultures and salinity levels (slope $=$ response variable; culture and sediment type $=$ categorical predictors). Initially, we evaluated and confirmed that the conditions of normality and homoscedasticity had been met, and then we applied the analysis of variance (Factorial ANOVA) and the Tukey's test a posteriori.

In addition, we verified the existence of significant differences $(P<0.05)$ among the total-N, total-P and organic matter content and the very fine sand, silt and clay percentages in the sediment of each estuarine portion. We also evaluated and confirmed that the assumptions were met; then, we applied the analysis of variance (one-way ANOVA), followed by Tukeýs test. The statistical analyses were performed using Statistica 7.1 software (SN AX505B150718FA) (StatSoft, 2005).

\section{Results}

The sediment salinity values in the three banks located on the Itanhaém River Estuary were significantly different, with higher salinity in the lower estuary, intermediate salinity in the middle estuary and lower salinity in the upper estuary (Table 1). We began using the approximate average values to note the salinity levels throughout this study, which were 26 (lower estuary), 12 (middle estuary) and 4 (upper estuary).

The granulometry of the banks located in the lower, middle and upper estuary were significantly different. The upper estuary sediment showed the smallest silt and clay percentage and the highest percentage of very fine sand (Table 1). The sediment total- $\mathrm{N}$ and total-P content were significantly greater in the middle estuary than in the upper and lower estuaries (Table 1).

The growth curves of the aboveground biomass of C. americanum (Fig. 2) and S. alterniflora (Fig. 3) show that the two species grew differently in different sediments and in a monoculture versus in a mixed culture. At salinity level 4, the growth of $C$. americanum was similar in the monoculture and the mixed culture, but at salinity levels 12 and 26, the growth of this species in the monoculture was higher than in the mixture. C. americanum exhibited stronger growth at salinity level 12 and in the monoculture (Fig. 2). At salinity level 4, S. alterniflora suffered a drastic reduction in aboveground biomass, reaching zero biomass. The growth of $S$. alterniflora was high in salinity levels 12 and 26 in both the monoculture and the mixed culture (Fig. 3).

Although salinity and nutrient levels may have changed during the experiment due to mechanisms of absorption, retention and excretion (Liphschitz et al., 1974; Kao et al., 2003; Céccoli et al., 2015), we consider that the results on the plant growth are consistent allowing the conclusions presented in this paper.

The results of the factorial ANOVA applied to the slope values of the variation in aboveground biomass of both species in the different treatments showed that for $C$. americanum, the interaction term was significant (Factorial ANOVA: culture-df: 1/F: 46.68/ $P<0.01$; sediment type-df: $2 / F: 38.68 / P<0.01$; interaction-df: $2 / F: 19.25 / P<0.01)$, indicating that the slope values were significantly different between culture and sediment type. Tukey's test indicated that the slope value was significantly higher in the treatment with intermediate-salinity level and in the monoculture than in the mixed culture. There was no significant difference between cultures at salinity levels 4 and 26 (Table 2). For S. alterniflora, the interaction term was not significant (Factorial ANOVA: culture-df: $1 / F: 0.58 / \mathrm{p}>0.05$; sediment 
Table 1 Mean values (standard deviation) of sediment salinity level, total-N, total-P and organic matter content and very fine sand, silt and clay percentage in the Lower, Middle and Upper Itanhaém River Estuary

\begin{tabular}{lcrr}
\hline & Lower estuary & Middle estuary & Upper estuary \\
\hline Salinity & $25.88(0.31) \mathrm{a}$ & $11.55(0.49) \mathrm{b}$ & $4.33(0.41) \mathrm{c}$ \\
Total-N (\%Dry mass) & $0.221(0.035) \mathrm{b}$ & $0.302(0.034) \mathrm{a}$ & $0.170(0.025) \mathrm{c}$ \\
Total-P (\%Dry mass) & $0.013(0.001) \mathrm{b}$ & $0.019(0.002) \mathrm{a}$ & $0.010(0.001) \mathrm{c}$ \\
Organic matter (\%Dry mass) & $9.14(0.77) \mathrm{b}$ & $13.80(1.67) \mathrm{a}$ & $6.21(1.45) \mathrm{c}$ \\
Very fine sand (\%) & $42.54(1.62) \mathrm{c}$ & $48.72(1.61) \mathrm{b}$ & $65.98(1.96) \mathrm{a}$ \\
Silt and clay $(\%)$ & $29.88(1.95) \mathrm{a}$ & $30.90(1.87) \mathrm{a}$ & $15.32(1.53) \mathrm{b}$ \\
\hline
\end{tabular}

Distinct letters indicate significant differences $(P<0.05)$

type-df: $2 / F: 92.98 / P<0.01$; interaction-df: $2 / F$ : $1.09 / \mathrm{p}>0.05$ ), indicating no significant difference between the slope values in the monoculture or mixed culture at all salinity levels (Table 3).

There was an increasing trend of the RAB of $S$. alterniflora and a concomitant reduction of the RAB of $C$. americanum in the mixed culture at salinity levels 12 and 26 until day 31; after this period, there was a relatively constant proportion of aboveground biomass throughout the experiment (Fig. 4). At salinity level 26 , the $S$. alterniflora proportion of aboveground biomass in the culture reached high values (between 0.77 and 0.87), and the opposite trend occurred at salinity level 4 , in which the RAB of $C$. americanum (between 0.64 and 0.98 ) increased while that of S. alterniflora decreased (Fig. 4).

The interaction term of the factorial ANOVA applied to the GBB of $C$. americanum (Factorial ANOVA: culture-df: $1 / F: 52.79 / P<0.01$; sediment type-df: $2 / F: 33.99 / P<0.01$; interaction-df: $2 / F$ : $7.60 / P<0.01$ ) and of $S$. alterniflora (Factorial ANOVA: culture-df: $1 / F: 18.29 / P<0.01$; sediment type-df: $2 / F: 226.94 / P<0.01$; interaction-df: $2 / F$ : $5.93 / P<0.05)$ was significant, indicating that the GBB of the two species was significantly different between culture and sediment type. Tukey's test indicated that the GBB of $C$. americanum was significantly higher, at salinity level 12 , and in the monoculture in relation to the GBB at salinity levels 4 and 26 in both in the monoculture and mixed culture (Fig. 5a). Tukey's test indicated that the GBB of S. alterniflora was also significantly higher at salinity level 12 and in monoculture in relation to the GBB in the other treatments. At salinity level 4, S. alterniflora presented a significantly lower GBB in both the monoculture and mixed culture than in the other treatments (Fig. 5b).

\section{Discussion}

Based on the results obtained in this experiment, we accepted the hypothesis that the competition-to-stress hypothesis may explain the distribution of $C$. americanum and $S$. alterniflora in the Itanhaém River Estuary but not as proposed by Crain et al. (2004) and Engels \& Jensen (2010). According to the hypothesis proposed by these authors, we hypothesized that the $S$. alterniflora halophyte could develop in low-salinity environments but not in the oligohaline environment due to the effect of the competition with $C$. americanum and that $C$. americanum would not occur in the lower estuary for being unable to tolerate higher salinity (salt stress). The aboveground biomass mortality and the reduced gain in belowground biomass of S. alterniflora observed in monoculture showed that this species does not grow in sediments with a lowsalinity level (salinity level 4). Thus, our results counter the studies that indicate greater halophyte growth with reduced salinity in the absence of competition (Crain et al., 2004; Touchette, 2006; Engels \& Jensen, 2010).

Some authors suggest that $S$. alterniflora requires relatively high concentrations of sulphur for growth (Stribling, 1997; Castillo et al., 2005). Because sulphate availability varies positively with salinity gradient in the environment (Stribling, 1997), the lower sulphate availability was probably a limiting factor to the development of S. alterniflora in the lowsalinity condition in our experiment. Furthermore, at the lower salinity level, we observed reduced sediment total-N and total-P availability. Some studies indicate that nitrogen is limiting to S. alterniflora (Smart \& Barko, 1980; Darby \& Turner, 2008), especially regarding the development of its aboveground fraction 

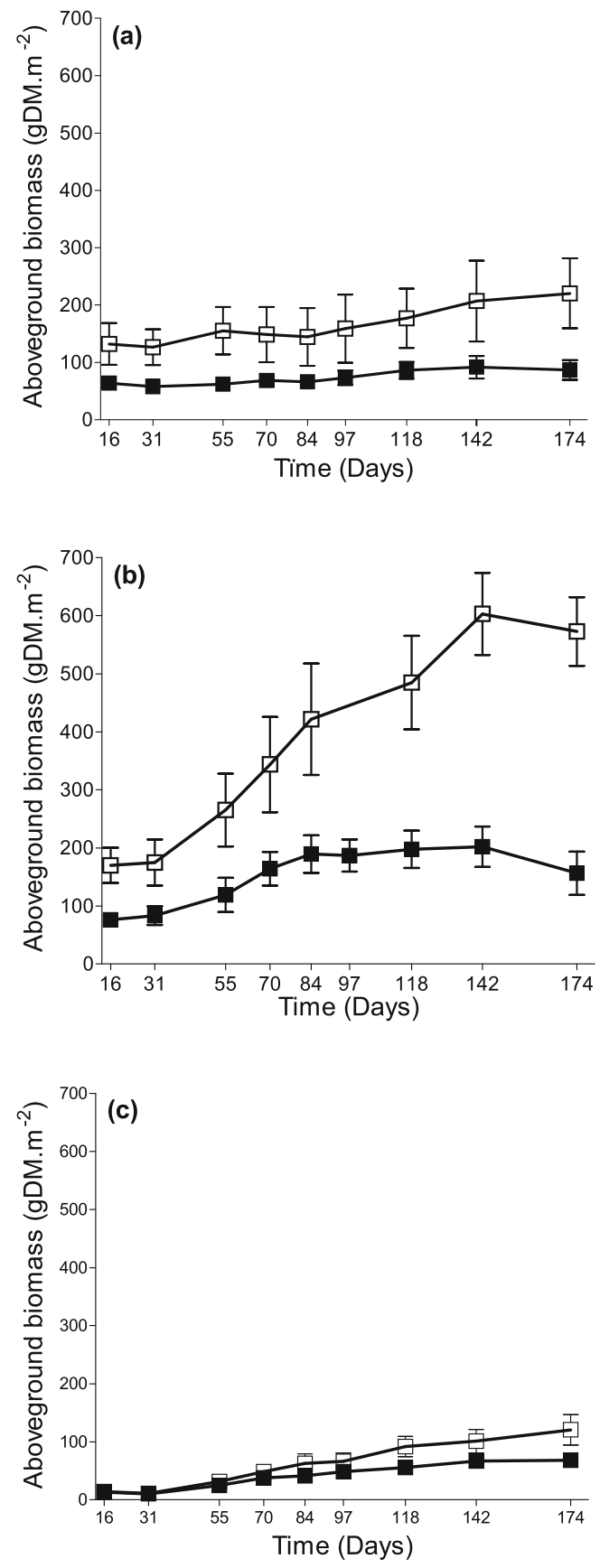

Fig. 2 Mean values and standard deviation of aboveground biomass and growth curves of $C$. americanum in the monoculture (open squares) and the mixed culture (black squares) at salinity levels 4 (a), 12 (b) and 26 (c)

(Darby \& Turner, 2008), whereas the belowground fraction tends to be limited by phosphorus. Sediments with a higher sand content and lower clay content are
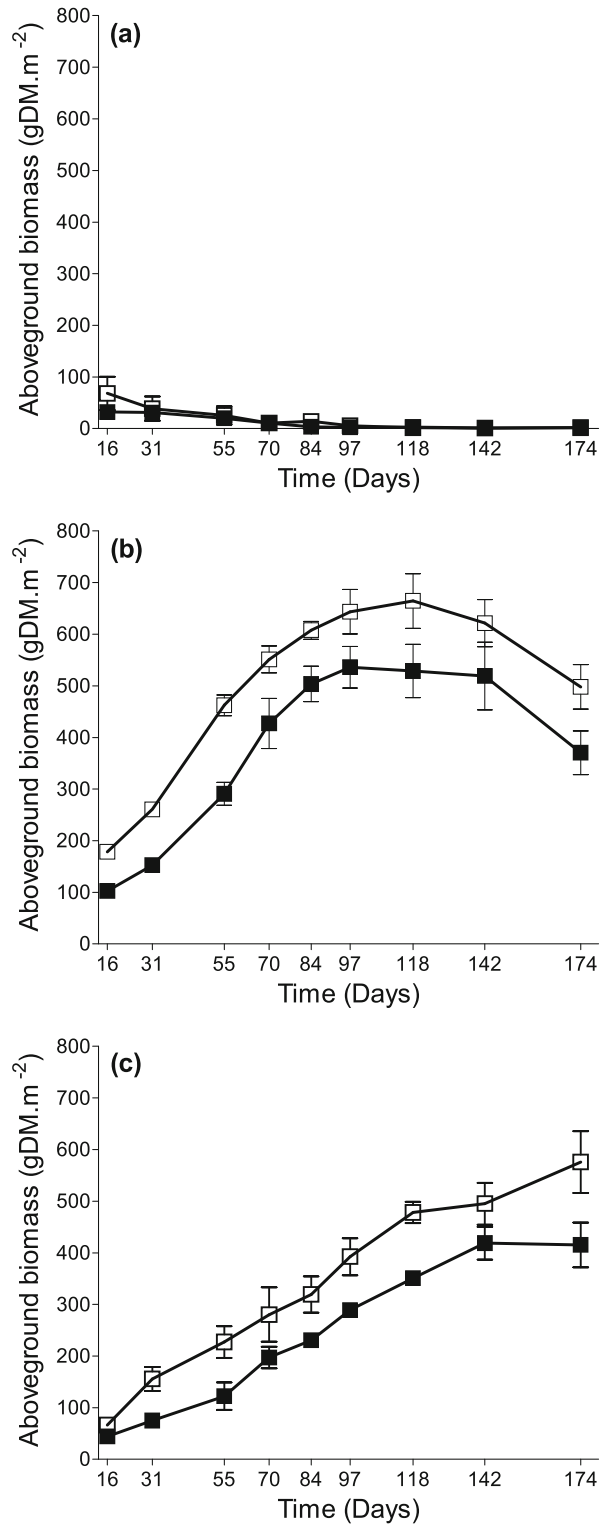

Fig. 3 Mean values and standard deviation of the aboveground biomass and growth curves of S. alterniflora in the monoculture (open square) and in the mixed culture (black square) at salinity levels 4 (a), 12 (b) and 26 (c)

also unfavourable to the growth of aquatic macrophytes (Touchette, 2006; Martin \& Coetzee, 2014). Tropical estuaries have higher nutrient availability and a lower salinity level than middle- and high-latitude estuaries (Eyre \& Balls, 1999). This fact may be related to the absence of $S$. alterniflora in oligohaline areas in our tropical estuary and to the presence of this species in oligohaline estuarine areas in temperate 
Table 2 Mean values (standard deviation) of the slope of the aboveground biomass variation (Slope) and coefficient of determination $\left(R^{2}\right)$ in the $C$. americanum monoculture and mixed culture from the values obtained from the adjustment of the linear regression model of each treatment replica

\begin{tabular}{lcll}
\hline Culture & Salinity & Slope & $R^{2}$ \\
\hline Monoculture & 4 & $0.594(0.315) \mathrm{b}$ & $0.71(0.23)$ \\
& 12 & $2.984(0.404) \mathrm{a}$ & $0.89(0.08)$ \\
& 26 & $0.741(0.241) \mathrm{b}$ & $0.96(0.01)$ \\
Mixed culture & 4 & $0.217(0,122) \mathrm{b}$ & $0.59(0.30)$ \\
& 12 & $0.704(0.213) \mathrm{b}$ & $0.52(0.13)$ \\
& 26 & $0.404(0.050) \mathrm{b}$ & $0.92(0.02)$
\end{tabular}

Distinct letters indicate significant differences $(P<0.05)$

Table 3 Mean values (standard deviation) of slope of the variation in aboveground biomass (Slope) and coefficient of determination $\left(R^{2}\right)$ in the $S$. alterniflora monoculture and mixed culture from the values obtained from the adjustment of the linear regression model of each treatment replica

\begin{tabular}{lcrl}
\hline Culture & Salinity & \multicolumn{1}{l}{ Slope } & \multicolumn{1}{l}{$R^{2}$} \\
\hline Monoculture & 4 & $-0.400(0.251) \mathrm{b}$ & $0.58(0.11)$ \\
& 12 & $2.331(0.489) \mathrm{a}$ & $0.46(0.10)$ \\
& 26 & $3.232(0.270) \mathrm{a}$ & $0.46(0.05)$ \\
Mixed culture & 4 & $-0.220(0.055) \mathrm{b}$ & $0.73(0.01)$ \\
& 12 & $2.226(0.510) \mathrm{a}$ & $0.44(0.09)$ \\
& 26 & $2.679(0.356) \mathrm{a}$ & $0.92(0.04)$ \\
\hline
\end{tabular}

Distinct letters indicate significant differences $(P<0.05)$

regions. Thus, the absence of S. alterniflora and its lack of growth under oligohaline conditions in the Itanhaém River Estuary can be justified by the limiting nutrients $(\mathrm{N}, \mathrm{P}$ and $\mathrm{S})$ associated with sediments with a lower silt and clay percentage and not because of its lower competitive ability in oligohaline environments.

In our experiment, $C$. americanum grew in sediments with higher salinity, which would allow the presence of this species in the lower estuary. Some authors have considered this species to be tolerant to salinity (Meerow et al., 2003; Ribeiro et al., 2011). In fact, in an estuary on the northern coast of São Paulo State (Brazil), C. americanum is the most abundant aquatic macrophyte species near the estuary mouth (Ribeiro et al., 2011). Our experimental results showed that the growth of $C$. americanum in monoculture was similar for both high- (26) and intermediate- (12) salinity levels, and we did not verify
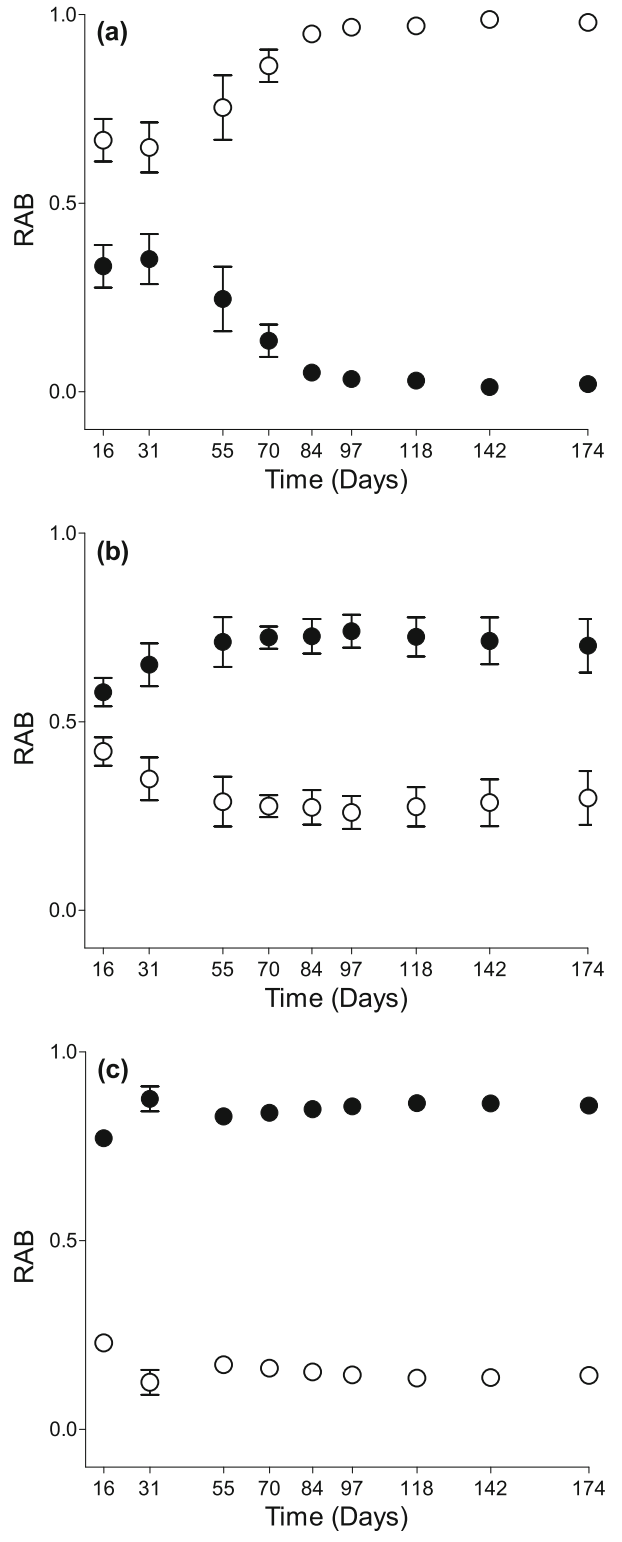

Fig. 4 Mean values and standard deviation of the relative aboveground biomass of $C$. americanum (open circle) and $S$. alterniflora (black circle) in the mixed culture at salinity levels 4 (a), 12 (b) and 26 (c)

significant differences between the slope values at salinity levels 26 and 4 . The gain in belowground biomass in the monoculture was not significantly different between salinity levels 26 and 4 either. These results indicate that this species can grow at high salinity. Our results also show that in sediments with higher salinity and in the mixed culture, the gain in belowground biomass of $C$. americanum is lower than 

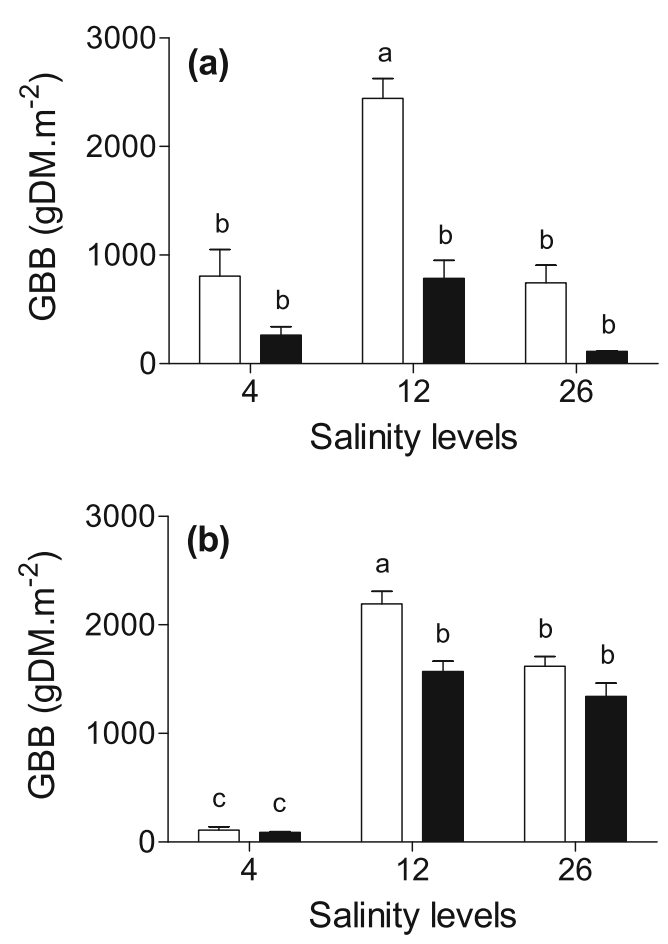

Fig. 5 Mean values and standard deviation of the Gain in Belowground Biomass (GBB) (g dry mass $\mathrm{m}^{-2}$ ) of $C$. americanum and $S$. alterniflora in the monoculture (white bar) and the mixed culture (black bar) at salinity levels 4, 12 and 26. Distinct letters indicate significant differences $(P<0.05)$

in the monoculture. In addition, the growth of this species at higher salinity and the mixed culture is lower than the growth in the monoculture, suggesting that the growth of this species under euryhaline conditions can be limited by S. alterniflora. In the mixed culture and at higher salinity levels, the aboveground biomass proportion of $S$. alterniflora was higher (0.77-0.87) than that of $C$. americanum (0.13-0.23), which indicates a tendency of asymmetrical competition. Asymmetrical competition has been found in experiments with other species of aquatic macrophytes (Henry-Silva \& Camargo, 2005; Yingbiao Zhi et al., 2007; van Gerven et al., 2015); thus, this type of interaction appears to be useful for explaining plant distribution in aquatic ecosystems. Thus, the absence of $C$. americanum in the lower Itanhaém River Estuary is probably due to competitive interaction with $S$. alterniflora, which is a more efficient competitor under conditions of higher salinity.

The estuarine portion with the mesohaline sediment, in which the mixed bank was located, has a higher availability of nutrients in relation to other portions, and in our experiment, this sediment proved to be more favourable for the development of aquatic macrophytes. In fact, both species reached high slope values and a high gain in belowground biomass in the monoculture at this salinity level. Similar results were observed in a study by Guo \& Pennings (2012), where under experimental conditions, the halophytes $S$. alterniflora and Batis maritima also showed high biomass under brackish conditions in a monoculture. Our results of the growth of $C$. americanum and $S$. alterniflora in the mixed culture at sediment salinity level 12 showed that the growth of $S$. alterniflora was not affected by the presence of $C$. americanum; however, its growth was reduced by the presence of S. alterniflora, while the species affected each other regarding belowground biomass. Thus, under mesohaline conditions, asymmetric competition occurs for the aboveground biomass and symmetrical competition occurs for the belowground biomass. These experimental results indicate that under mesohaline conditions, $S$. alterniflora has a competitive advantage over $C$. americanum in relation to the aboveground fraction, which conflicts with the occurrence of mixed banks in the intermediate portion of the Itanhaém River Estuary. However, although both species occur in the estuarine portion, $S$. alterniflora occurs in deeper locations and is therefore subject to greater variation in water level, whereas $C$. americanum occurs in shallower locations. It is probable that the variation in water level is responsible for the occurrence of $C$. americanum in shallower locations and is subject to less variation in water level. In fact, Ribeiro et al. (2011) observed that in areas subjected to greater flooding, this species is absent in an estuary located near the Itanhaém River Estuary.

Our results differed from those expected according to the competition-to-stress hypothesis (Crain et al., 2004; Engels \& Jensen, 2010); that is, our results from a tropical estuary differed from those in middle- or highlatitude estuaries or salt marshes (Crain et al., 2004; Pennings et al., 2005; Engels \& Jensen, 2010; Guo \& Pennings, 2012). Some factors can drive the geographic variation of ecological process because some abiotic factors are extremely affected by climatic factors (Pennings \& Bertness, 1999). Tropical estuaries might be much wetter with more annual precipitation compared with estuaries in temperate regions. For example, in the Itanhaém River Estuary, the mean annual 
precipitation is $2,030 \mathrm{~mm}$ while in the Elbe Estuary (Germany), the study area of Engels \& Jensen (2010), this value was $750 \mathrm{~mm}$. Thus, in tropical estuaries, the effect of high solar radiation intensity is attenuated by high precipitation; therefore, salt stress is alleviated in such environments (Eyre \& Balls, 1999). Another question is that tropical estuaries are more nutrient limited than the temperate estuaries (He \& Silliman, 2015) because the constant rainfall in the tropics causes the leaching of sediment material (Eyre \& Balls, 1999). Therefore, as suggested by Pennings et al. (2005), we can highlight that the mechanisms responsible for plant zonation in estuaries (competition and stress) may be general, but the importance of the processes and abiotic factors that cause stress (salinity, flooding and nutrient availability) can vary geographically.

In conclusion, our data confirm that the competition-to-stress hypothesis explains the distribution of $S$. alterniflora and C. americanum in the Itanhaém River Estuary but not as proposed by Crain et al. (2004) and Engels \& Jensen (2010). These authors proposed that some species are excluded from the nearest locations to the seashore due to abiotic stress, while other species are excluded from the upper estuary due to competition. However, our results show that the abiotic stress is responsible for the absence of $S$. alterniflora in the upper estuary probably as a result of the low concentrations of nitrogen and phosphorus, the low organic matter percentage and the higher sand percentage. The competition between the two species is responsible for the absence of $C$. americanum in the lower estuary probably because, in this portion of the estuary, S. alterniflora is a better competitor.

Acknowledgements We thank Carlos Fernando Sanches and Amarílis Brandão de Paiva, M.S., for assistance with the experiment, Cristiane Akemi Umetsu, Ph.D., for helping in the statistical analyses and Leonardo Farage Cancian, Ph.D., for drawing up the map of the study area.

\section{References}

Barbour, M. G., 1978. The effect of competition and salinity at growth of a salt marsh species. Oecologia 37: 93-99.

Bertness, M. D., 1991. Zonation of Spartina patens and Spartina alterniflora in a New England salt marsh. Ecology 72: 138-148.

Bertness, M. D., L. Gough \& S. W. Shumway, 1992. Salt tolerances and the distribution of fugitive salt marsh plants. Ecology 73: 1842-1851.
Biudes, J. F. V. \& A. F. M. Camargo, 2006. Changes in biomass, chemical composition and nutritive value of Spartina alterniflora due to organic pollution in the Itanhaém River Basin (SP, Brazil). Brazilian Journal of Biology 66: 781-789.

Burgos-León, A. M., D. Valdés, M. E. Vega \& O. Defeo, 2013. Spatial struturing of submerged aquatic vegetation in an estuarine habitat of the Gulf of Mexico. Journal of the Marine Biological Association of the United Kingdom 93: 855-866.

Camargo, A. F. M. \& E. R. Florentino, 2000. Population dynamics and net primary production of the aquatic macrophytes Nymphaea rudgeana C.F. Mey in a lotic environment of the Itanhaém River Basin (SP, Brazil). Brazilian Journal of Biology 60: 83-92.

Camargo, A. F. M., L. A. Pereira \& A. M. M. Pereira, 2002. Ecologia da bacia hidrográfica do rio Itanhaém. In Schiavetti, A. \& A. F. M. Camargo (eds), Conceitos de Bacias Hidrográficas. Editus, Ilhéus.

Castillo, J. M., A. E. Rubio-Casal, S. Redondo, A. A. IvarezLopez, T. Luque, C. Luque, F. J. Nieva, E. M. Castellanos $\&$ M. E. Figueroa, 2005. Short-term responses to salinity of an invasive cordgrass. Biological Invasions 7: 29-35.

Céccoli, G., J. Ramos, V. Pilatti, I. Dellaferrera, J. C. Tivano, E. Taleisnik \& A. C. Vegetti, 2015. Salt glands in the Poaceae family and their relationship to salinity tolerance. The Botanical Review 81: 162-178.

Crain, C. M., B. R. Silliman, S. L. Bertness \& M. D. Bertness, 2004. Physical and biotic drivers of plant distribution across estuarine salinity gradients. Ecology 85: 2539-2549.

Darby, F. A. \& R. E. Turner, 2008. Below- and aboveground biomass of Spartina alterniflora: response to nutrient addition in a Louisiana Salt Marsh. Estuaries and Coasts 31: $326-334$.

Engels, J. G. \& K. Jensen, 2010. Role of biotic interactions and physical factors in determining the distribution of marsh species along an estuarine salinity gradient. Oikos 119: 679-685.

Eyre, B. \& P. Balls, 1999. A comparative study of nutrient behavior along the salinity gradient of tropical and temperate estuaries. Estuaries 22: 313-326.

French, T. D. \& E. P. A. Chambers, 1996. Habitat partitioning in riverine macrophytes communities. Freshwater Biology 36: 509-520.

Golterman, H. L., R. S. Climo \& M. A. M. Ohnstad, 1978. Methods for Physical and Chemical Analysis of Freshwaters. IBP, Oxford.

GraphPad Software, 2007. Prism (Data Analysis Software System), Version 5.

Greenwood, M. E. \& G. R. MacFarlane, 2009. Effects of salinity on competitive interactions between two juncus species. Aquatic Botany 90: 23-29.

Guo, H. \& S. C. Pennings, 2012. Mechanisms mediating plant distributions across estuarine landscapes in a low-latitude tidal estuary. Ecology 93: 90-100.

He, Q. \& B. R. Silliman, 2015. Biogeographic consequences of nutrient enrichment for plant-herbivore interactions in coastal wetlands. Ecology Letters 18: 462-471.

Hellquist, C. E. \& R. A. Black, 2010. The influence of intertidal zone and native vegetation on the survival and growth of 
Spartina anglica in Northern Puget Sound, WA, USA. In Ayres, D. R., D. W. Kerr, S. D. Ericson \& P. R. Olofson (eds), Proceedings of the Third International Conference on Invasive Spartina, 8-10 November 2004. San Francisco Estuary Invasive Spartina Project of the California State Coastal Conservancy, Oakland, San Francisco, CA.

Henry-Silva, G. G. \& A. F. M. Camargo, 2005. Interações ecológicas entre as macrófitas aquáticas flutuantes Eichhornia crassipes e Pistia stratiotes. Hoehnea 32: 445-452.

Kao, J. T., J. E. Titus \& W. X. Zhu, 2003. Differential nitrogen and phosphorus retention by five wetland plant species. Wetlands 23: 979-987.

Kenkel, N. C., A. L. Mcllraith, C. A. Burchill \& G. Jones, 1991. Competition and the response of three plant species to a salinity gradient. Canadian Journal of Botany 69: 2497-2502.

La Peyre, M. K. G., J. B. Grace, E. Hahn \& I. A. Mendelssohn, 2001. The importance of competition in regulating plant species abundance along a salinity gradient. Ecology 82 : 62-69.

Lipscshitz, N., A. Shomer-llan, A. Eshel \& Y. Waisel, 1974. Salt glands on leaves of Rhodes grass (Chlorisgayana Kth). Annals of Botany 38: 459-462.

Mackereth, F. J., H. J. Heron \& J. F. Talling, 1978. Water Analysis: Some Revised Methods for Limnologists. Freshwater Biological Association, London.

Martin, G. D. \& J. A. Coetzee, 2014. Competition between two aquatic macrophytes, Lagarosiphon major (Ridley) Moss (Hydrocharitaceae) and Myriophyllum spicatum Linnaeus (Haloragaceae) as influenced by substrate sediment and nutrients. Aquatic Botany 114: 1-11.

Medeiros, D. L., D. S. White \& B. L. Howes, 2013. Replacement of Phragmites australis by Spartina alterniflora: the role of competition and salinity. Wetlands 33: 421-430.

Meerow, A. W., D. J. Lehmiller \& J. L. Clayton, 2003. Phylogeny and biogeography of Crinum L. (Amaryllidaceae) inferred from nuclear and limited plastic non-coding DNA sequences. Botanical Journal of Linnean Society 141: 349-363.

Pennings, S. C. \& M. D. Bertness, 1999. Using latitudinal variation to examine effects on climate on coastal salt marsh pattern and process. Current Topics in Wetland Biogeochemistry 3: 100-111.
Pennings, S. C., M. B. Grant \& M. D. Bertness, 2005. Plant zonation in low-latitude salt marshes: disentangling the roles of flooding, salinity and competition. Journal of Ecology 93: 159-167.

Ribeiro, J. P., R. S. Matsumoto, L. K. Takao, A. C. Peret \& M. I. S. Lima, 2011. Spatial distribution of Crinum americanum in the tropical blind estuary: hydrologic, edaphic and biotic drivers. Environmental and Experimental Botany 71: 287-291.

Ribeiro, J. P., R. S. Matsumoto, L. K. Takao \& M. I. S. Lima, 2015. Plant zonation in a tropical irregular estuary: can large occurrence zones be explained by a tradeoff model? Brazilian Journal of Biology 75: 511-516.

Rodríguez-Gallego, L., V. Sabaj, S. Masciadri, C. Kruk, R. Arocena \& D. Conde, 2015. Salinity as a major driver for submerged aquatic vegetation in coastal lagoons: a multiyear analysis in the subtropical Laguna de Rocha. Estuaries and Coasts 38: 451-465.

Smart, R. M. \& J. W. Barko, 1980. Nitrogen nutrition and salinity tolerance of Distichlis spicata and Spartina alterniflora. Ecology 61: 630-638.

StatSoft, INC., 2005. Statistica (Data Analysis Software System), Version 7.1.

Stribling, J. M., 1997. The relative importance of sulfate availability in the growth of Spartina alterniflora and Spartina cynosuroides. Aquatic Botany 56: 131-143.

Suguio, K., 1973. Introdução à sedimentologia. EDUSP, São Paulo.

Tararam, A. S. \& Y. Wakabara, 1987. Benthic fauna living on Spartina altemiflora of Cananéia estuarine lagoon $\left(2 \mathrm{~S} 002^{\prime} \mathrm{S}-47^{\circ} 56^{\prime} \mathrm{W}\right)$. Boletim do Instituto Oceanográfico 35: 103-113.

Touchette, B. W., 2006. Salt tolerance in a Juncus roemerianus brackish marsh: spatial variations in plant water relations. Journal of Experimental Marine Biology and Ecology 337: $1-12$.

van Gerven, L. P. A., J. J. M. de Klein, D. J. Gerla, B. W. Kooi, J. J. Kuiper \& W. M. Mooij, 2015. Competition for light and nutrients in layered communities of aquatic plants. The American Naturalist 186: 72-83.

Zhi, Y., H. Li, S. An, L. Zhao, C. Zhou \& Z. Deng, 2007. Interspecific competition: Spartina alterniflora is replacing Spartina anglica in coastal China. Estuarine, Coastal and Shelf Science 74: 437-448. 